\title{
Capability Engineering - An Analysis of Perspectives
}

\author{
Michael J de C. Henshaw, \\ Systems Engineering Division, \\ Loughborough University, LE12 3TU \\ Peter Lister, \\ Harmonic Ltd, The Hatchery, \\ Eaglewood Park, Ilminster, \\ Somerset,TA19 9DQ \\ Alan D Harding, \\ BAE Systems, Brennan House, PO \\ Box 87, Farnborough Aerospace Centre, \\ Farnborough, Hampshire, GU14 6YU
}

\author{
Duncan Kemp, \\ Rail value for money study
}

Floor 5, 55 Victoria Street, London

\author{
Malcolm Touchin, \\ Systems Engineering Innovation Centre \\ Holywell Park, Loughborough University, LE11 3TU \\ Copyright (C 2011 by Michael Henshaw, Duncan Kemp, Peter Lister, Andrew Daw, Alan Harding, Andrew Farncombe, Malcolm \\ Touchin. Published and used by INCOSE with permission.
}

\begin{abstract}
The terms 'capability' and 'capability engineering' are now widely used across industry and in government procurement, but it is clear that different communities use the terms with similar, but distinctly different meanings. Using a soft systems methodological approach, an INCOSE UK working group has identified eight perspectives of capability, which have been related to Ring's value cycle and the Hitchins' five layer model of systems engineering. It is asserted that capability is the ability to do something and that capability engineering is the overarching approach that links value, purpose, and solution of a systems problem. It is equivalent to layers 1-4 of Hitchins' Five Layer Model and is equivalent to an holistic perspective of systems engineering. There are significant practice and examples of capability engineering from (at least) the UK rail provision, defence, and Information Services and it is the view of the working group that further INCOSE guidance may be needed to ensure engineers are properly equipped to deal with capability and capability engineering.
\end{abstract}

\section{Introduction}

The term 'capability' is widely used across many industrial sectors and has begun to take on various specific meanings across, and even within, those sectors. Terms such as capability-based acquisition, capability engineering and management, Through Life Capability Management, capability sponsor, etc. are now ubiquitous in the UK Ministry of Defence and elsewhere. Indeed, capability improvement is assessed within all UK public sector procurement across Government (Smith, 2007). The proliferation of capability-speak, the multiple and diverse uses of the term capability and its clear association with systems have led INCOSE UK to ask the question: what needs to be done to improve our understanding and approach to capability, and how can systems engineering help? (Lister, 2009). A Capability Working Group (CWG) was launched in 2009 to address this question 
and a Perspectives Analysis Sub-Group (PASG) conducted a study into the worldviews of capability in order to record the range of definitions currently used and to understand the relationships between them.

Discussions in the CWG underlined the multitude of meanings of capability across and within communities and it was concluded that, whilst it would not be feasible to force agreement on a common definition, it would be desirable to derive the characteristics that describe how "capability-based" procurements are different (or not) from "business as usual". To demystify capability, Checkland's Soft Systems Methodology (Checkland \& Scholes, 1999) has been used as an approach (i.e. research framework) to capture the different worldviews and to develop root definitions through which capability, and more particularly capability engineering, can be characterized.

This paper reports on the scope of systems engineering and how capability engineering is related to it. Whilst clarifying the concept of capability engineering, this paper should be regarded as a starting point from which further development of an appropriate language and guidance can be developed. The PASG makes a number of recommendations to INCOSE UK which, if adopted, will enable INCOSE members to understand capability engineering within the broader systems context and so discuss capability through well-defined parameters.

\section{WORLDVIEWS OF CAPABILITY}

Soft Systems Methodology (SSM) is a technique through which activities that take place in complex socio-technical environments may be mapped in order to understand the pertaining situation and assist managers to identify means to improve it. A very important tenet of SSM is the recognition that different individuals within a situation have different worldviews of it. To be explicit; individuals within the same situation will interpret it differently according to factors such as their background and culture, their role within the situation, their previous experiences, etc. Thus, the PASG study has been approached based on the belief that individuals working in aspects of capability will not necessarily hold the same worldview of capability. All worldviews are treated as valid.

Throughout the rest of this paper the term 'Weltanschauung' will be used rather than 'worldview' to capture more accurately the meaning of this concept as defined in SSM. Weltanschauung(en) are the worldview(s) that makes the system transformation of SSM meaningful. The choice of the word Weltanschauung by Checkland and his associates is significant; the word does not translate directly into English but is used to convey the notion of a belief held by an individual or a society which makes the root definition meaningful. The nature of the transformation (T) for a particular situation will be different according to the different Weltanschauungen that exist for that situation (Checkland \& Scholes, 1999).

The basis upon which this work is conducted is that capability is a polyseme ${ }^{1}$ and the purpose of the activity is to:

- Develop a clear understanding of the different types of capability engineering

- Begin to develop a high level language for capability engineering.

The first of these objectives has been addressed through two brainstorming sessions in which the different meanings were captured using the CATWOE (Customer, Actor, Transformation, Weltanschauung, Owner, and Environment) mnemonic of Checkland's SSM. This implies that it is possible to describe a system in which a meaning of capability or capability engineering is apparent. Having defined the system and its context through use of the CATWOE, a root definition has been constructed that incorporates the meaning of capability or capability engineering. It is appropriate to note that, having used the CATWOE

\footnotetext{
${ }^{1}$ A polyseme is a word with multiple distinct, but related, meanings
} 
to construct a root definition, it is not possible then to test that definition using CATWOE (Wilson, 2001). It is important to understand that SSM is not being used here to conduct action research, but simply as a helpful framework and approach through which different views of a situation may be assembled and discussed; i.e. the work comprises only the first three of the seven steps of Checkland's SSM .

The root definitions are provided below, with a commentary on each. For each definition, the sense in which the word capability is used is identified through a name, or type.

The members of the sub-group had expertise in defence, aerospace, infrastructure, information systems and rail. Examples to illustrate the definitions, and subsequent analyses, are drawn from the defence and rail domains.

This paper also addresses, but doesn't complete, the second objective, above, by clarifying capability engineering and initiating the development of an appropriate language.

\section{Root Definitions}

The numbering of the root definitions below is not significant and reflects only the order in which the Perspectives Analysis sub-group generated them; those which are very closely related but have subtle differences are distinguished by $a, b$.

W1 - Equipment has Capability: Described by a system in which: A buyer defines the needs of users against which suppliers design and develop equipment that has capability, which assumes the user's skill, the effectiveness of the supply chain and the equipment's maintained state at the time at which the capability is realized.

This Weltanschauung is equivalent to a resource-based view of capability in which the resources provide some ability to 'do something' within defined performance parameters; e.g. a train with the capability to carry 700 people or an aircraft capable of flying at a Mach 4 . This definition does not take account of the context explicitly (it is merely assumed implicitly through familiarity) and is based largely on performance characteristics.

This definition concerns only capability, not capability engineering. This type of capability is referred to as Equipment Capability.

W2 - Capability used to describe solution independent requirements: Described by a system in which: A buyer attempts to translate a set of explicit user wants into a written set of solution independent requirements within the constraints of procurement policy, against which a supplier may generate system design options to satisfy the capability need, that is defined and constrained by the context in which the equipment is used, the user's skill, the effectiveness of the supply chain and the equipment's maintained state at the time at which the capability is realized.

This Weltanschauung concerns an idealized view of systems innovation and development, in which a buyer (customer) states a required capability with no narrowing of available solutions through pre-conceived ideas about the solution. In many places where good systems engineering practice is advocated, there will be advice to the effect that user requirements should be written in a solution independent fashion. A few moments thought will show that, in general, this is unachievable, because a solution starting point will almost always be assumed from which the solution will be evolved. It is very rare that the starting point has no assumptions about what the solution will be like. In fact, it is more a question of getting the right level of abstraction in the requirements to encourage innovation. Thus it is important to write them in a form that minimizes constraints so as not to preclude trading opportunities.

An example of this Weltanschauung could be specifying the required capability as a transport capability able to carry 10,000 people per hour from Glasgow to London in a journey time of less than ninety minutes.

This definition is mainly concerned with capability engineering in terms of solution 
development. In some sectors this type of activity is referred to as Capability Planning.

W3 - Deciding / balancing in which capability to invest: Described by a system in which: A planner or strategist continually and continuously determines capability needs and the funds available, and an architect designs a programme to deliver systems to meet the capability needs, in order to decide in which capabilities fund holders should invest to achieve an overall capability balanced across users' needs, within the constraints of the pertaining political environment, commercial structures (supply chain) and taking account of existing systems.

This is trading across capabilities to maximize the value of investment in terms of a high level capability. For instance, a surveillance capability (high level) may be achieved through a balance of investment across airborne, satellite, and terrestrial observation capabilities (lower levels), or a transport system (high level) built from a balance of investment across road, rail, and air transport capabilities (lower level). This requires the available capabilities to be considered and an holistic view taken of their cost, their potential performance across a range of contexts, and their interaction with each other.

This definition is concerned with capability engineering, as opposed to capability, but this type of activity is properly referred to as Capability Trade-off.

W4 - Service provision

W4a - Delivering specific business services: Described by a system in which: A service provider delivers specific business services to a service recipient (e.g. a passenger); achieved by the provider, users, and functional responsible person defining the quality of service required, designing the service, transitioning capability components into service, operating the service, and continuously improving the service, in line with the provider's strategic plans and the extant operating conditions.

The emphasis is on service development and provision based on organization, reconfiguration or adaptation of available resources, rather than the wholesale development of the resources themselves. Examples include implementing a new London to Bristol timetable using alternative rolling stock or an improved air defence system incorporating an updated tactical data-link.

W4b - Developing fallback services to be used at a future date: This is a variation on the above, but includes elements of W3, in which investment supports development of potential (or contingency) capabilities to improve robustness against changing circumstances; for example, developing a fallback timetable to cope with one line blocked between London and Reading. This Weltanschauung is identified separately because the design and development for contingent services are often approached differently to those for immediate and continuous use; for instance, they will also include periodic testing and exercises. Although in most cases services are designed for immediate use, this special type is stored for contingent use.

The basic W4 root definition is, thus, changed as follows: Described by a system in which: A service provider designs and develops specific fallback services for a service recipient (e.g. a passenger); achieved by the provider, users, and functional responsible person defining the quality of service required, designing the fallback service, and storing for transition of capability components into service, operating the service in line with the provider's strategic plans and the extant operating conditions.

The definitions implied by W4 incorporate both capability (the delivered service) and capability engineering (activities of delivery).

The type of capability to which the W4a definition refers is concerned with defining, developing, and using services continuously and is called Service Capability.

The type of capability to which the W4b definition refers is concerned with defining, developing and storing services and is referred to as Contingent Service Capability. 
W5 - Reconfiguring available assets, people and processes quickly to meet current circumstances: Described by a system in which: A user understands that circumstances have changed and picks, modifies and implements the most appropriate plan to meet the specific circumstances by reconfiguring the available assets, people and processes within an appropriate timeframe to meet the current circumstances.

This refers to the user rapidly adapting the available resources to meet an immediate need. This treats the ability to reconfigure resources as a component of capability in its own right; the level of capability the user possesses is, then, associated with the variety of circumstances (contexts) in which the user may maintain capability ${ }^{2}$. A key characteristic of this type of capability is the tempo associated with reconfiguration, i.e. agility is a feature of such capability. The differences between W5 and W4 are that the adaptation in W5 is carried out by users, not by the service providers, in the operational context, and that the adaptation is unanticipated.

This definition incorporates both capability and capability engineering. This type of activity is referred to as Dynamic Capability Reconfiguration.

W6 - Developing a capability (all Components of Capability) solution: Described by a system in which: An enterprise of users, suppliers, and buyers develop and operate a capability solution across (and incorporating) all contributing components, by deploying all appropriate systems engineering approaches/techniques to understand the problem, investigate options, develop, integrate, transition to service, operate, maintain, renew, upgrade and dispose of the components that together meet the need.

This is the overarching Weltanschauung that covers the development, and ongoing use of the capability. There are many who believe that these features are part of systems engineering; below we describe this as holistic systems engineering. Examples include "Develop, use and sustain a new high speed rail transport capability between London and the Midlands" or "Renew the UK independent nuclear deterrent." This explicitly considers the multi-organizational nature of the enterprise and associated constraints (e.g. PESTLE ${ }^{3}$ ) through which capability is developed.

This definition relates only to capability engineering. There does not appear to be a universally adopted term for this activity, but some communities of thought would term it "capability engineering" and some "systems engineering". To distinguish this activity from those associated with other Weltanschauungen, it is termed Capability Systems Engineering in this paper.

W7 - Managing the interdependencies between capabilities: Described by a system in which: strategists (supported by all $\mathrm{CoC}^{4}$ owners) develop, maintain and ensure implementation of an integrated plan in order to manage the interdependencies between all CoC changes, across all capabilities and all business service delivery, in order to support strategy, finance, and CoC owners.

This is a level above the individual capability level - understanding what capabilities can be used together and planning the whole capability budget. It is often called strategic or enterprise planning. Examples include "Develop, maintain and use the integrated rolling stock and route utilization plan" or "Develop, maintain and use the UK military capability plan". It includes elements of W3 in terms of balance of investment, but adopts a more connected view of capabilities, recognising that many capabilities may be built from common components of capability.

\footnotetext{
${ }^{2}$ Wang, Klein, \& Jiang (2007) have termed a firm's abilities to demonstrate timely responsiveness to changing environments as dynamic capabilities.

${ }^{3}$ PESTLE stands for Political, Economic, Sociological, Technological, Legal, Environmental; it is an analysis framework for organizations' environmental impact to guide strategic decision making.

${ }^{4}$ Components of Capability
} 
This definition concerns capability engineering. This activity is referred to as Enterprise Planning.

W8a - Organizations have capability: Described by a system in which: an organization controls resources that it can configure to maximize its performance in the creation, by its employees, of products and/or services that are desired by consumers/users, in order to maximize the return on investment of its shareholders (stakeholders).

This is a view common in the manufacturing, and other, sectors that considers capability to be based simply on the resources available to an organization. Within the systems community it is sometimes called organizational capability ${ }^{5}$. The context in which the capability is realized is usually considered to be somewhat static and the capability is gauged by performance (e.g. $\mathrm{CMMI}^{6}$ ). This view is essentially resource-based, in the sense that more resources are often considered to equate to greater capability.

This definition is primarily concerned with capability, although the notion of configuring resources could be considered to be a form of capability engineering. This type of capability is referred to as Organizational Capability.

W8b - Capabilities emerge through processes of interaction between individuals, groups and organizations: Described by a system in which: consumers of products and services benefit from improved commercial offerings of companies whose operational capabilities are enhanced through the relationships with their supply chains; the overall capability of the supply chain being revealed through the interactions between the organizations within the supply chain that represents an extended knowledge enterprise.

This is also a view recognized within the manufacturing sector, which recognizes organizations as simultaneously possessing resource-based capability, which they term operational capability (W8a), and relational capabilities that rely on good choices of supply chain partners that enhance the overall capabilities through the additional knowledge that they bring to the enterprise ${ }^{7}$. Examples might include an organization with a solid productbuilding capability enhanced by another with more effective marketing capabilities, in order to secure a greater portion of the market. This view of capability places a high value on tacit knowledge. It also recognizes that resources are passive until enacted by the interaction between parties and, hence, capability only emerges at the time of that interaction.

This definition is primarily concerned with capability, although it does also incorporate aspects of capability engineering. This type of capability is referred to as Relational Capability.

\section{Mapping the Weltanschauungen}

To understand the relationship of the Weltanschauungen to each other in order to a) check commonality and b) relate the perspectives to systems engineering, they have been mapped to Ring's Value Cycle (Ring, 2002). The value cycle for managing and engineering capability is shown in Figure 1 and the mapping of the Weltanschauungen to the cycle in Figure 2. Care is needed in the interpretation of this figure, because the Ws (Weltanschauungen) have been mapped to the system of interest, but the Ws by definition refer to different contexts. Nevertheless, this mapping will be helpful for understanding the origin of particular Weltanschauungen held by individuals according to the part of the value cycle in which they are primarily active.

Referring to Figure 1, it is noted that the lower half of the diagram (from 'characterize capability' anticlockwise to 'verify capability') represents the traditional systems engineering

\footnotetext{
${ }^{5}$ It is sometimes referred to as operational capability (Tan, Kannan, \& Narasimhan, 2006; Croom \& Batchelor, 1997)

${ }^{6}$ Capability Maturity Model Integration

${ }^{7}$ Croom \& Batchelor (1997) have defined these the distinct terms of "operational" and "relational" capabilities.
} 
"V". But the upper half of the diagram - which we term the client side - focuses on the value. It is in this part of the cycle that most of the Weltanschauungen for capability engineering reside. Thus, we note that capability engineering is frequently viewed as the value proposition that the constituent systems of capability provide (realized or in potential). And herein lies the crux of the matter with respect to the question: isn't capability engineering just plain old systems engineering after all? It all depends on whether one views systems engineering as traditional systems engineering (by which we mean process-based design and build) or encompassing a wider set of activities including systems / holistic thinking. For subscribers to W6, capability engineering is simply plain old systems engineering, but for subscribers to the other views, capability engineering represents a separate set of activities outside traditional systems engineering.

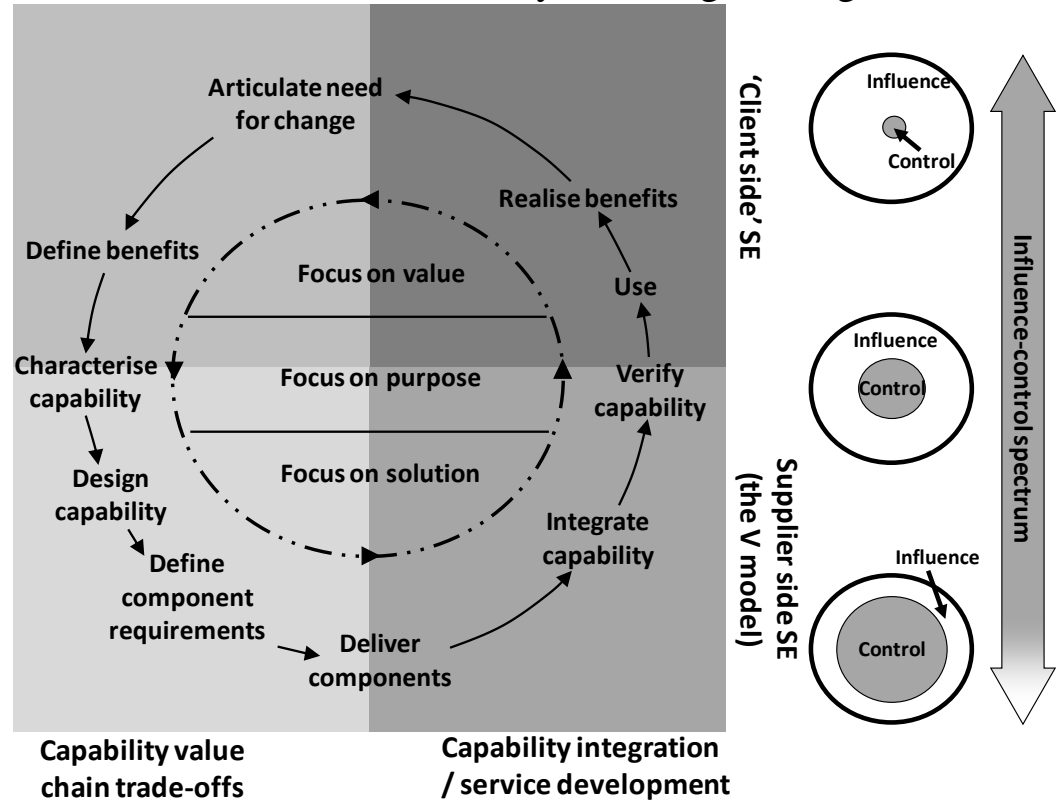

Figure 1: Ring's value cycle

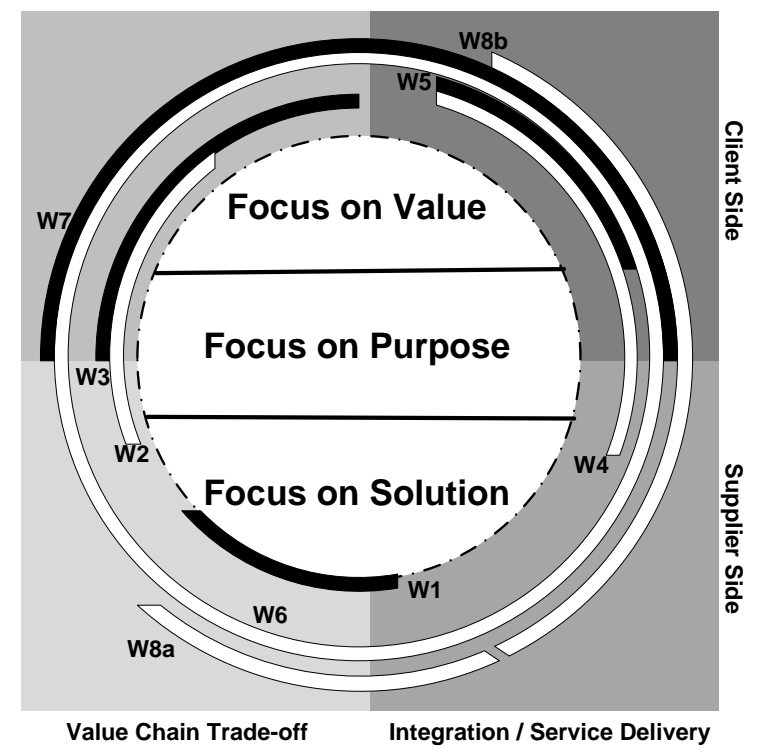

Figure 2: The Weltanschauungen of capability engineering mapped to Ring's value cycle

$\mathrm{W} 1$ and $\mathrm{W} 8$ (a and $\mathrm{b}$ ) predominantly refer to perspectives on capability, whereas W2, $\mathrm{W} 3, \mathrm{~W} 5, \mathrm{~W} 6$, and W7 refer to activities that are conceived to be capability engineering. W4 
( $a$ and $b$ ), as expressed here, refers to both capability and capability engineering.

The actors associated with each activity are shown in Table 1 . It is hypothesized that the Weltanschauungen described above are broadly those to which the associated actors subscribe. This may explain the differences of opinion as to the meanings of capability and capability engineering.

\begin{tabular}{|c|c|c|c|c|c|c|c|c|}
\hline & W1: & W2: & W3: & W4: & W5: & W6: & W7: & W8: \\
\hline & 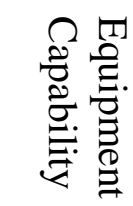 & 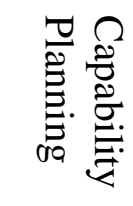 & 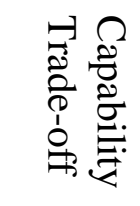 & 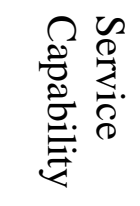 & 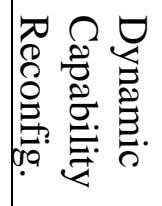 & 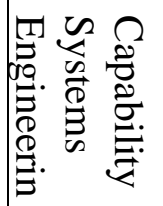 & 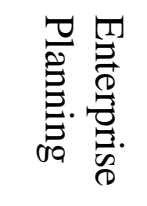 & 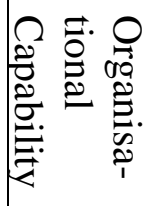 \\
\hline User & & $\checkmark$ & & $\checkmark$ & $\checkmark$ & $\checkmark$ & & \\
\hline Buyer & $\checkmark$ & $\checkmark$ & & & & $\checkmark$ & & \\
\hline Architect & & $\checkmark$ & $\checkmark$ & & & $\checkmark$ & & \\
\hline Cap. Owner & & $V$ & & & & $\checkmark$ & $\checkmark$ & \\
\hline Strategist & & $\checkmark$ & $\checkmark$ & & & & $\checkmark$ & \\
\hline Supplier & $\checkmark$ & & & & & $\checkmark$ & & \\
\hline $\begin{array}{l}\text { Service } \\
\text { Provider }\end{array}$ & & & & $\checkmark$ & & & & \\
\hline Employees & & & & & & & & $V$ \\
\hline Customer & & & & & & & & $V$ \\
\hline
\end{tabular}

Table 1: Actors associated with particular Weltanschauungen

\section{Components of Capability (CoC)}

The terms Components of Capability (CoC) and (Defence) Lines of Development (DLoD) essentially have the same meaning. We have chosen to use the term Components of Capability as being more generally meaningful across different industry sectors, and is supposed to include all other such descriptions (e.g. TEPIDOIL ${ }^{8}$ in UK MoD, DOTMLPF ${ }^{9}$ in US DoD, $\mathrm{FIC}^{10}$ in Australian Dept. of Defence, etc.). To state the obvious, the components of capability are all the systems and sub-systems required to build and realize capability. At a top level the $\mathrm{CoC}$ might be considered to fall into the categories of tools (equipment), people, processes, infrastructure, and support services; but within each capability delivering enterprise they tend to be partitioned in-line with the chosen concept of organization (i.e. how the organization chooses to do business). To illustrate this, the UK Defence Lines of Development and the Rail Components of Capability are shown together in Table 2; the coverage is broadly the same. These are mapped to the five basic components of capability of people, process, support services, equipment, and infrastructure. In some cases the categories overlap; for instance organization encompasses both people and processes.

Capability tends to fall into two types; those that are designed to be used 'when required' (i.e. held as potential capability) and are not truly tested in context except at the time of use (e.g. nuclear deterrence, contingent rail timetabling) and those that are exercised and tested every day (e.g. provision of a continuous recognized air picture and an air policing capability,

\footnotetext{
${ }^{8}$ UK MoD Defence Lines of Development: Training, Equipment, Personnel, Information, Doctrine (and concepts), Organization, Infrastructure, Logistics.

${ }^{9}$ Doctrine, Organization, Training, Materiel, Leadership and Education, Personnel and Facilities

${ }^{10}$ Australian Fundamental Inputs to Capability: Command and Management, Organization, Major Systems, Personnel, Supplies, Support, Facilities, Collective Training
} 
daily transporting 535,000 people into London by train). W4 (Service Capability) is a specific reference to this with a) Service Capability and b) Contingent Service Capability.

\begin{tabular}{|c|c|c|}
\hline & UK Defence Lines of Development & Rail Components of Capability \\
\hline \multirow[b]{2}{*}{ People } & $\begin{array}{l}\text { Personnel (sufficient capable and } \\
\text { motivated people) }\end{array}$ & \multirow{2}{*}{$\begin{array}{l}\text { People (numbers, skills, knowledge } \\
\text { and attributes) }\end{array}$} \\
\hline & $\begin{array}{l}\text { Training (practise, develop and } \\
\text { validate common military doctrine) }\end{array}$ & \\
\hline & $\begin{array}{l}\text { Organization (all operational and non- } \\
\text { operational relationships between } \\
\text { people and groups) }\end{array}$ & $\begin{array}{l}\text { Organization (roles and responsibility, } \\
\text { contracts, interfaces, behaviours and } \\
\text { agreements) }\end{array}$ \\
\hline \multirow[t]{2}{*}{ Process } & \multirow{2}{*}{$\begin{array}{l}\text { Concepts and Doctrine (concept of } \\
\text { capability use to execute activities; } \\
\text { principles by which military forces } \\
\text { guide their actions) }\end{array}$} & $\begin{array}{l}\text { Safety (safety cases, Safety } \\
\text { management systems, roles and } \\
\text { responsibilities) }\end{array}$ \\
\hline & & \multirow{2}{*}{$\begin{array}{l}\text { Operations (timetable, services, } \\
\text { command and control, revisionary } \\
\text { modes, procedures and processes) }\end{array}$} \\
\hline \multirow{3}{*}{ Support Service } & $\begin{array}{l}\text { Information (data, information, and } \\
\text { knowledge) }\end{array}$ & \\
\hline & \multirow{2}{*}{$\begin{array}{l}\text { Logistics (operational movement and } \\
\text { maintenance of military forces and } \\
\text { materiel) }\end{array}$} & $\begin{array}{l}\text { Maintenance (processes, information, } \\
\text { approach, roles and responsibilities, } \\
\text { contracts) }\end{array}$ \\
\hline & & $\begin{array}{l}\text { Logistics and supply (Supply networks, } \\
\text { capacity, lean/resilience approaches) }\end{array}$ \\
\hline Tools/Equipment & $\begin{array}{l}\text { Equipment (military systems and } \\
\text { weapons) }\end{array}$ & $\begin{array}{l}\text { Rolling stock (bogies, bodyshell, } \\
\text { pantograph, signalling, engines) }\end{array}$ \\
\hline Infrastructure & $\begin{array}{l}\text { Infrastructure (fixed, permanent } \\
\text { buildings and structures, land, utilities } \\
\text { and facility management services) }\end{array}$ & $\begin{array}{l}\text { Infrastructure (track, signalling, power, } \\
\text { stations, gauging) }\end{array}$ \\
\hline
\end{tabular}

Table 2: Defence Lines of Development and Rail Components of Capability

\section{The Enterprise Nature of Capability Engineering}

The term enterprise is used to imply a networked set of autonomous (commercial) units whose transaction costs are lower if they cluster together (Atkinson \& Moffat, 2005) and which all contribute to the delivery of capability. The mapping of the Weltanschauungen to the Ring Value Cycle (Figure 1) indicates that most Ws are in the domain of focus on value, which is the domain where organizations can exert influence but have little overall control. In general, this can be considered to be the domain in which delivery relies on multiorganization enterprises, which can be characterized as networks of autonomous organizations collaborating to achieve shared goals. The nature of capability delivery is also represented schematically in Figure 1 (RHS) in terms of the relative need for an organization to exert influence or control.

\section{The concept of Capability Engineering}

The foregoing discussion leads to the concept of capability engineering captured in the entity relationship diagram (ERD) of Figure 3.

Capability contributes to enterprise goals, where an enterprise is generally considered to consist of multiple autonomous organizations linked through sharing of those goals. Capability is realized through systems that are built from capability components (equipment, processes, people, support services and infrastructure). Those same systems provide the services through which organizations deliver capability. The enterprise goals are set in 
response to contextualized environmental factors that can be described by the well known PESTLE $^{3}$ factors.

The relationship of the entity called 'capability' to other entities in Figure 3 is primarily consistent with W6, although it is also appropriate to W2, W3, W4, W5, and W7. It is not consistent with W1 (equipment capability) or W8 (organizational capability).

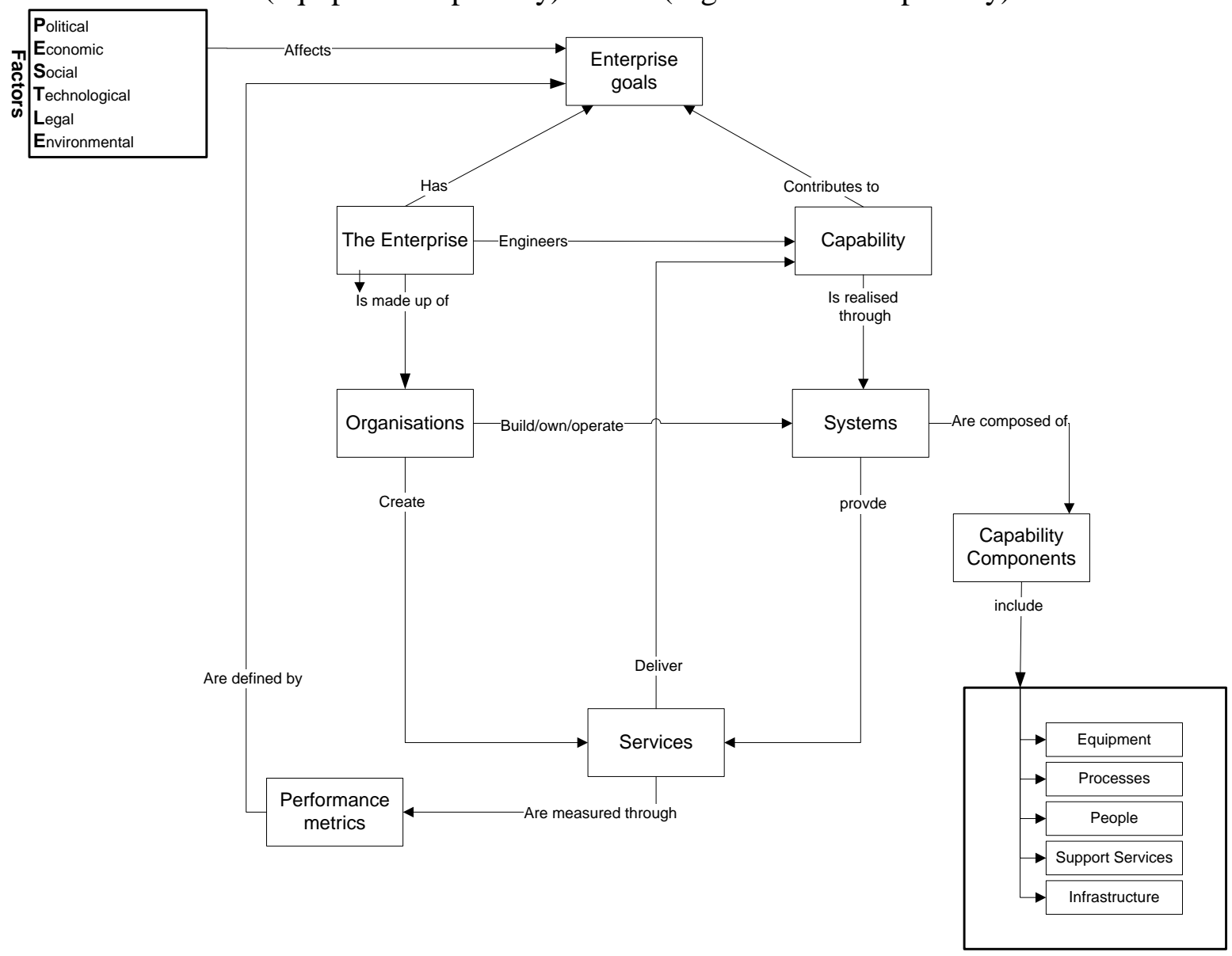

Figure 3: Entity Relationship Diagram for the Concept of Capability Engineering

\section{Rationalization of Weltanschauungen}

Within an enterprise, different roles will typically be associated with different parts of the value cycle (see Figure 2 ). The entities associated with each Weltanschauung are illustrated in the abbreviated ERDs shown in Figure 4. Thus we might suppose that an end user or the design engineer might hold W1 (equipment capability), being very much concerned with product engineering. Similarly, members of delivery teams might be expected to hold W4, being very much concerned with the services they deliver and the management of the systems through which those services are delivered to clients.

Figure 4 shows the narrow system of interest, upon which the actors for that particular Weltanschauung will focus (black), and the wider system of interest (grey), which includes the aspects that they must take into consideration. It is noted that PESTLE falls outside the narrow system of interest for all cases. This is because, whilst the capabilities developed may influence the PESTLE factors, in general the actors have no means of engineering them. PESTLE factors are, for the capability actors, the environmental context in which capability must be developed and maintained. 


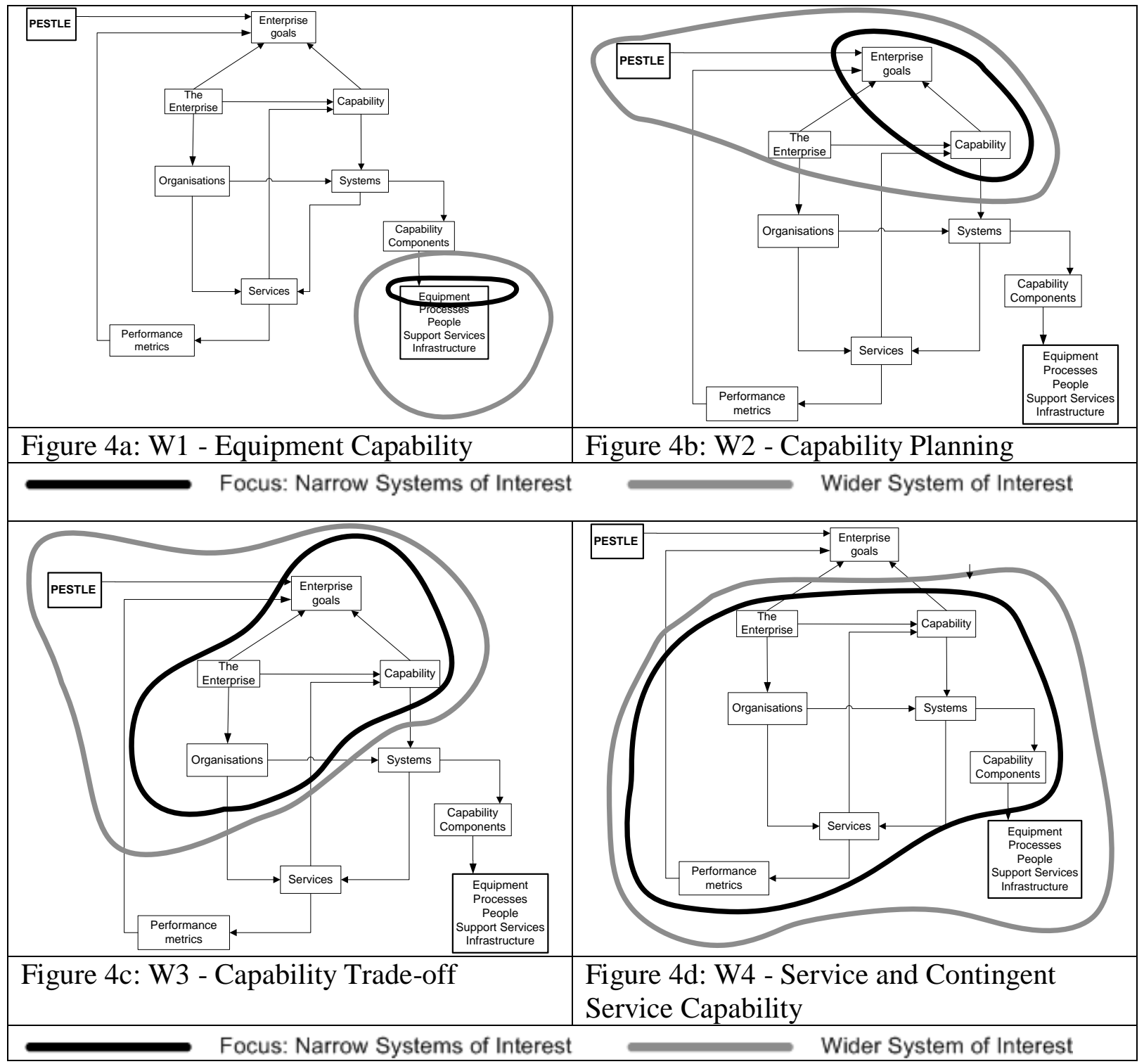

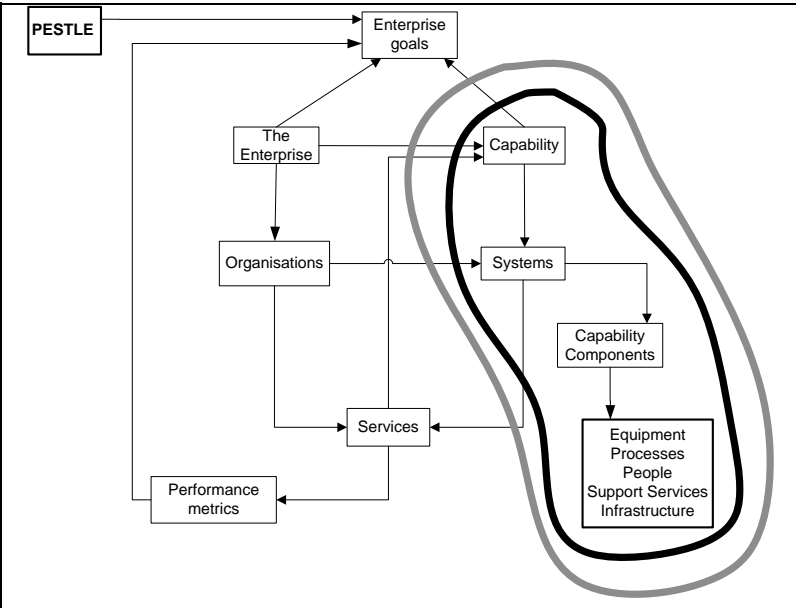

Figure 4e: W5 - Dynamic Capability Reconfiguration

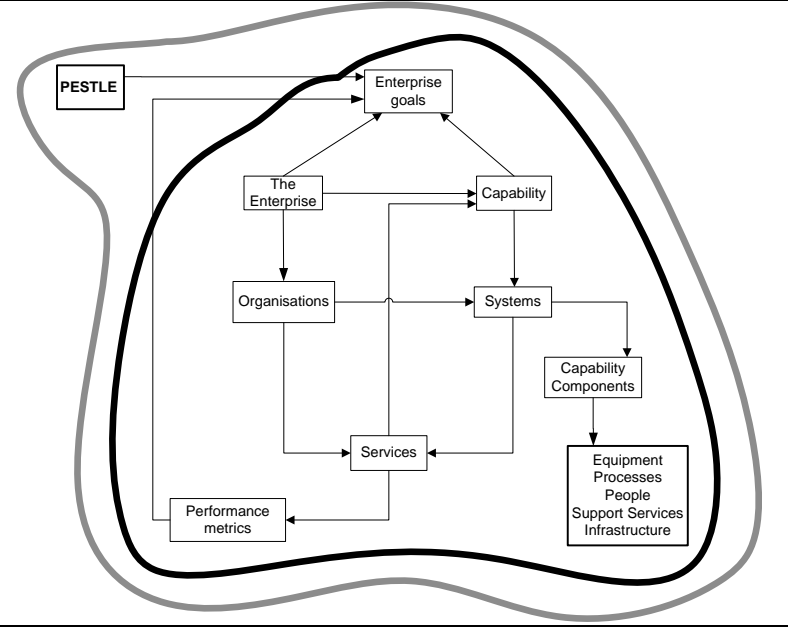

Figure 4f: W6 - Capability Systems Engineering 


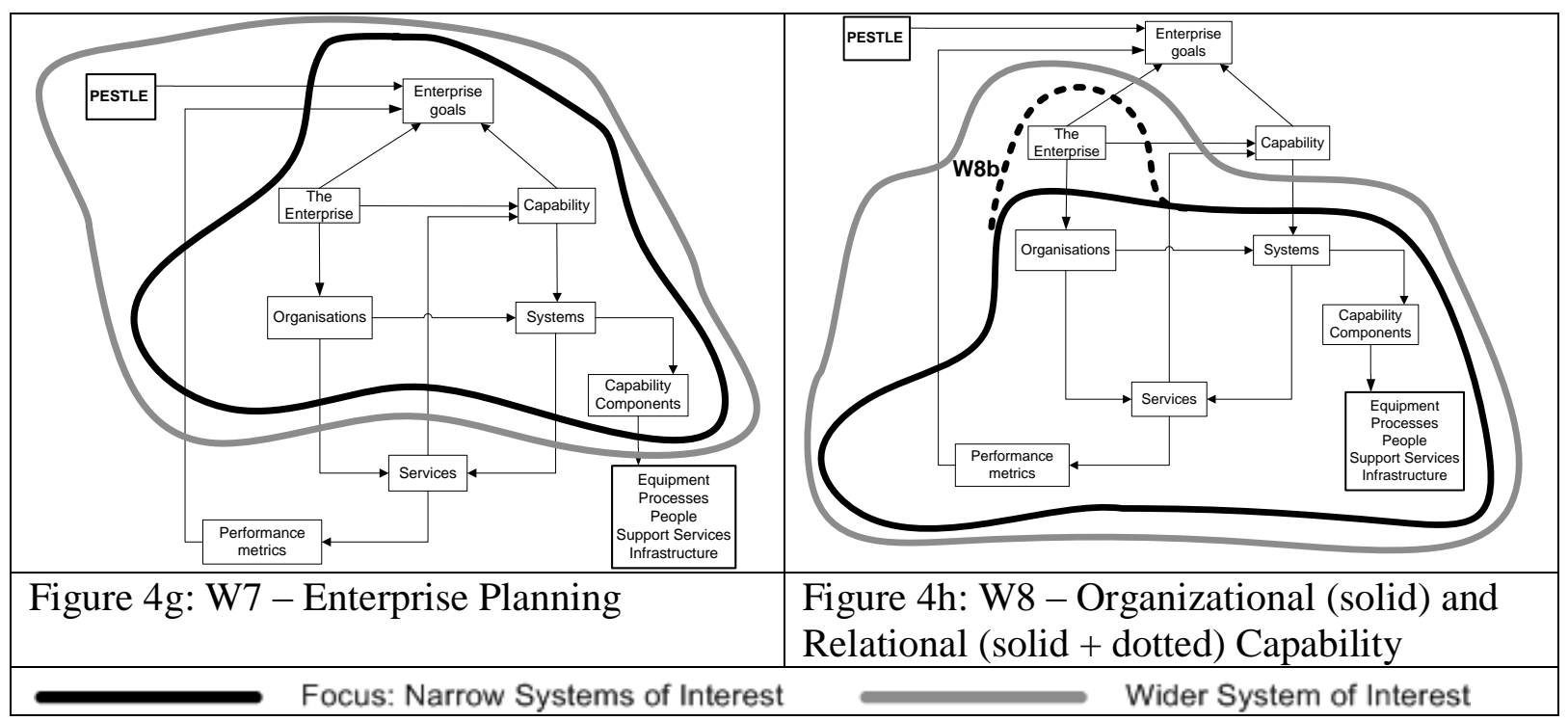

Figure 4: Mapping of Weltanschauungen onto ERD

The head of capability or his/her capability architect is likely to hold W6 and be concerned with the enterprise goals and the whole systems engineering approach to filling capability gaps, whereas an operator (e.g. front line command in military context) is likely to hold W5, in which available resources configured to meet defined capability needs must be rapidly reconfigured to maintain that capability in the face of a changing environment. Other Weltanschauungen are associated with the enterprise, rather than the engineering, aspects of capability realization, with a typical holder of W2 (capability planning) being the UK Policy \& Programme Steering Board, and of W3, the Joint Capabilities Board that must balance capability cost across the enterprise goals through trade-off between capabilities (W3).

Finally, W8 is likely to be the perspective of contracted organizations that believe capability to be a property of their resources and supply chain relationships; i.e. of the organizations themselves.

It is worthwhile noting that, whilst many of the speculative examples of groups/individuals (above) that might hold a particular Weltanschauung may have a systems perspective, few would subscribe to the title of Systems Engineer.

\section{The relationship of Capability Engineering to Systems Engineering}

The discussion so far has identified Weltanschauungen of capability engineering and related these first to the Ring Value Cycle (Ring, 2002) and then to each other through mapping onto an ERD. Consideration of actors in the capability engineering activities has led to the conclusion that there are multiple perspectives of the scope of both capability engineering and systems engineering, which explains the diversity of opinion about the nature of capability engineering and its relationship to systems engineering. These perspectives are explored below through the lens of the Hitchins' Five Layer Model of systems engineering (Hitchins, 1994)

The relationship of capability engineering to systems engineering necessarily depends on the view taken of what actually constitutes systems engineering. This uncovers differences between an idealized understanding of what systems engineering should be and what it actually is as practised, and also cultural differences in the manner in which the discipline has evolved. It is, however, clear that most Weltanschauungen consider capability engineering to be much broader than the systems engineering of products, but narrower in scope than the 
wider socio-technical systems identified as layer 5 in Hitchins' Five Layer Model ${ }^{11}$ (Hitchins, 1994). Some would understand capability engineering to be the engineering activity in the techno-social, as opposed to socio-technical, domain.

Based on the mapping of Figure 4, the Weltanschauungen for capability engineering are related to the Hitchins' Five Layer Model of systems engineering in Figure 5.

\begin{tabular}{|c|c|c|c|c|c|}
\hline $\begin{array}{l}\text { Hitchins Systems } \\
\text { Engineering } \\
\text { Lavers }\end{array}$ & $\begin{array}{c}\text { Product } \\
\text { Perspective }\end{array}$ & $\begin{array}{c}\text { Service } \\
\text { Perspective }\end{array}$ & $\begin{array}{c}\text { System } \\
\text { Perspective }\end{array}$ & $\begin{array}{l}\text { Enterprise } \\
\text { Perspective }\end{array}$ & $\begin{array}{c}\text { Holistic Systems } \\
\text { Engineering } \\
\text { Perspective }\end{array}$ \\
\hline $\begin{array}{l}\text { Layer 5: Socio- } \\
\text { Economic }\end{array}$ & & & & & 站 \\
\hline $\begin{array}{l}\text { Layer 4: Industrial } \\
\text { Systems } \\
\text { Engineering }\end{array}$ & & & & & \\
\hline $\begin{array}{l}\text { Layer 3: Business } \\
\text { Systems } \\
\text { Engineering }\end{array}$ & & W4 & & & W6 \\
\hline $\begin{array}{l}\text { Layer 2: System } \\
\text { Layer }\end{array}$ & & & & & \\
\hline $\begin{array}{l}\text { Layer 1: Product } \\
\text { Layer }\end{array}$ & W1 & & & & \\
\hline
\end{tabular}

Figure 5: Weltanschauungen of capability engineering as related to the Hitchins' Five Layer Model of systems engineering

The reader will recall that the root definition for $\mathrm{W} 1$ (equipment capability) relates only to capability and not to capability engineering, so this could be termed a product perspective.

The activity described by the root definition that includes W4 (service and contingent service capability) clearly represents a service perspective of capability engineering. This perspective does not include the creation of products (layer 1), but is concerned with the configuration of components of capability into services (layers 2 and 3 ).

W5 (dynamic capability reconfiguration) concerns an activity of systems rearrangement and this is considered to be an operational perspective of capability engineering. In general, this is mainly focused on layer 2 (system layer), but may also include reconfiguration at the product layer, depending on the context.

W2 (capability planning), W3 (capability trade-off), and W7 (enterprise planning), are all consistent with an enterprise perspective of capability engineering. These capability engineering activities are mainly covered by layers 3 and 4 .

W8 (organizational/relational capability) concerns capability, not capability engineering, but is noted to reside within the enterprise perspective nonetheless.

W6 (capability systems engineering) covers the most comprehensive range of activities (Figure 4f) and similarly the greatest range of layers (1-4 in Figure 5). The Perspectives Analysis sub-group observe that systems engineering is frequently portrayed as limited to layers 1 and 2 of the five layer model, but capability systems engineering (W6) is a perspective of capability engineering that is the equivalent of an Holistic Systems

\footnotetext{
${ }^{11}$ The layers are defined in Appendix A
} 
Engineering perspective. If this perspective is accepted, then the merit of capability engineering as a recognized activity within many contemporary enterprises will be to reaffirm the holistic view of systems engineering and to encourage a rekindled emphasis to be put on layers 3 and 4 in the understanding of, and education in, systems engineering.

\section{Conclusions}

The Perspectives Analysis sub-group of CWG has drawn the following conclusions from the evidence presented above.

1. It is the group's view that capability is the ability to do something; it is not a synonym for a system function or system purpose. Clearly there are some perspectives of capability that contradict this (W1).

2. A corollary of the statement above is that capability engineering is significantly different from product systems engineering and broader than (though it incorporates) the process perspective of systems engineering.

3. Capability engineering is very similar in scope to views of systems engineering such as Ring's Value Cycle (Ring, 2002) and layers 1-4 of Hitchins' Five Layer Model (Hitchins, 1994). That is to say, capability engineering is equivalent to an holistic perspective of systems engineering.

4. Capability engineering is the overarching approach that links value, purpose, and solution of a systems problem.

5. As such, capability engineering comprises mindset (holistic thinking, assumptions), trade-offs, design, processes, values and policy, and outcomes.

6. Capability is realized through a combination of components that include hard (equipment) and soft (people and processes) systems together with supporting services and infrastructure.

7. The processes for capability engineering are largely the same as traditional systems engineering, but the mindset and system boundary are different.

8. There are significant practice and examples of capability engineering from (at least) the UK rail provision, defence, and Information Services.

9. One's Weltanschauung of capability engineering is clearly dependent on where one draws the systems boundary. It is the view of the Perspectives Analysis sub-group that the most appropriate place to draw the systems boundary for capability engineering is to enclose layers 1-4 of the Hitchins' Five Layer Model of systems engineering.

10. Capability and capability engineering are important concepts that reaffirm the holistic view of systems engineering; this may imply the need for further INCOSE guidance at the higher Hitchins' layers (3 and 4).

\section{References}

Atkinson, S. R., \& Moffat, J. (2005). Agile Organization. CCRP.

Checkland, P., \& Scholes, J. (1999). Soft Systems Methodology in Action. Wiley.

Croom, S., \& Batchelor, J. (1997). The development of strategic capabilities - an interaction view. Integrated Manufacturing Systems , 8 (5), 299-312.

Hitchins, D. K. (1994). Managing Systems Creation. Engineering Management Journal , 8188.

Lister, P. (2009). INCOSE UK - Capabiltiy Working Group - Record of the Launch Meeting Held on 16 Septmenber 2009 at UWE Bristol. INCOSE UK.

Ring, J. (2002). Toward an ontology of systems engineering. INSIGHT , 5 (1), 19-22.

Smith, N. (2007). Procurement Capability Review Programme - Tranche One Report. Office 
of Government Commerce. London: HM Treasury.

Tan, K. C., Kannan, V. R., \& Narasimhan, R. (2006). The impact of operations capability on firm performance. International Journal of Production Research , 1 - 22.

Wang, E., Klein, G., \& Jiang, J. J. (2007). IT support in manufacturing firms for a knowledge management dynamic capability link to performance. International Journal of Production Research , 45 (11), 2419-2434.

Wilson, B. (2001). Soft Systems Methodology - Conceptual Model Building and its Contribution. Chichester: John Wiley \& Co.

Yourdon, E. (1989). Modern Structured Analysis. Engelwood Cliffs, NJ: Prentice-Hall.

\section{Acknowledgements}

The authors acknowledge helpful discussions with Derek Price, David Wright, John K Davies, James Martin, Jack Ring, and Hillary Sillitto.

\section{Appendix A - Hitchins Systems Engineering Five Layer Model (Hitchins, 1994)}

Layer 5: Socio-Economic, the stuff of regulation and government control

Layer 4: Industrial Systems Engineering, or engineering of complete supply chains/circles. Many industries make a socio-economic system. A global wealth creation philosophy.

Layer 3: Business Systems Engineering - many businesses make an industry. At this Layer, systems engineering seeks to optimize performance somewhat independent of other businesses

Layer 2: Project or System Layer. Many projects make a Business. Western engineermanagers operate at this Layer, principally making complex artefacts.

Layer 1: Product Layer. Many products make a system. The tangible artefact Layer. Many engineers and their institutions consider this to be the only "real" systems engineering

\section{Biographies}

Michael J de $\mathbf{C}$ Henshaw is Professor of systems engineering at Loughborough University (UK), where he leads the engineering systems of systems group. His research and teaching focuses on integration and management of complex socio-technical systems, with a particular emphasis on the challenges of through-life management of systems and capabilities. Prof. Henshaw is a member of the INCOSE UK Advisory Board and a co-chair of the IEEE Technical Committee for systems of systems.

Duncan Kemp is a systems engineer and programme manager with over twenty years experience in the defence and transportation sectors. He is currently the lead systems engineer for rail in the UK Department for Transport (DfT) and team leader for asset and supply chain management for the McNulty review of value for money in GB railway. Duncan is responsible for improving strategic whole life, whole system, decision making within rail; supporting current and future rail programmes; and, growing the engineering competence in DfT and the rail industry.

Peter Lister is Head of Capability (Systems Engineering) at Harmonic Ltd. He has spent his engineering career in industry, initially and mainly in the Aerospace and Defence domains, but including a 5 year period in Railway Signaling. He has been a member of INCOSE since 1994 and was President of the UK Chapter from 1999 to 2001.

Andrew J Daw is a Past President of INCOSE UK, a Visiting Professor of Systems Engineering at the University of Strathclyde in Glasgow and presently is the Head of TLCM Services for Harmonic Ltd, an independent Professional Services company. He has major project experience, such as the UK Aircraft Carrier programme, and most recently has been 
instrumental in the design, development and deployment of an Information Management based Decision Support and visualisation environment to assist UK Defence Acquisition.

Alan D Harding is the Chief Systems Engineer in BAE Systems Strategic Capability Solutions (Capability Development) group. He is responsible for the strategy and evolution of the TRAiDETM approach to capability-based decision making, working closely with the team of Capability Consultants engaged with UK MOD. Alan chairs the BAE Systems P\&S/I Systems Engineering for TLCM Working Group. He represents BAE Systems on the INCOSE International Corporate Advisory Board and he chairs the INCOSE UK Advisory Board.

Andrew Farncombe is Technical Director of INCOSE UK and a Visiting Professor of Systems Engineering at Cranfield University in the UK. He is an experienced Systems Engineer and has held senior technical and management positions including Technical Director in major UK Defence and Aerospace companies. During this time he led the development of one of the company's first publication on Systems Engineering. His consultancy work (within the Transportation, Aerospace, Defence and Electronics sectors) includes Systems Engineering process development and its application to projects.

Malcolm Touchin is the Principal Consultant at the Systems Engineering Innovation Centre, based at Loughborough University (UK). He has taken a significant role in developing BAE Systems' understanding and application of Systems of Systems Engineering to the challenges emerging from the UK MoD's Through Life Capability Management and similar initiatives. 